\title{
ADVANCED CERAMICS: INTRINSIC AND EXTRINSIC FACTORS
}

Open Engineering Collaboration*†

October 25, 2020

\begin{abstract}
The efficiency of electronic devices based on advanced ceramics is related to the optimization of the material's properties. In this paper, we discuss the intrinsic and extrinsic factors that influence the properties of advanced ceramics.
\end{abstract}

keywords: Ceramics; Ceramic processing; Ceramic properties; Advanced materials.

The most updated version of this paper is available at https://osf .io/xt7h6/download

\section{Introduction}

1. Advanced ceramics are characterized due to their optical, mechanical, thermal, electrical, multiferroic, magnetic, and ferroelectric properties $[1-3]$.

2. Electronic devices use one or more properties of (1) [4-6].

*All authors with their affiliations appear at the end of this paper.

†Corresponding author: andre@selfchargebox.com | Open Engineering Collaboration 


\section{Methods}

3. A systematic literature review was carried out in the area of materials science and engineering.

\section{Results and Discussion}

4. The advanced ceramics properties (1) are related to its intrinsic and extrinsic factors [7].

5. Intrinsic factors are composition, crystalline symmetries, charge/polarization distributions, cell parameters, homogeneity, and crystallinity [8-10].

6. Extrinsic factors are grain size, ferroelectric domain, texture, density, and porosity [11-13].

7. (5) and (6) are modified by the processing route, purity of precursors, stoichiometric strategies, and sintering processes $[14,15]$.

8. (5) and (6) must be tuned to optimize the ceramic properties (1), as shown in Fig. 1 [16].

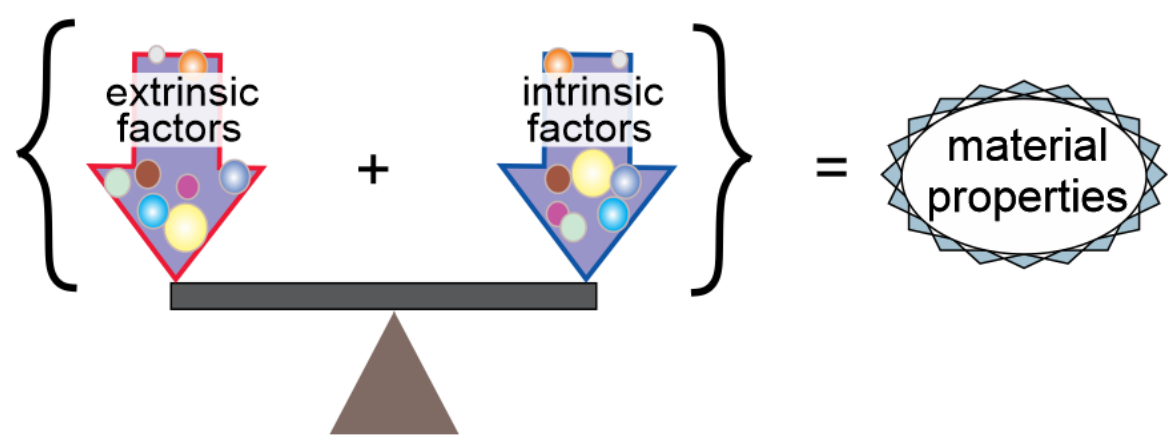

Figure 1: Balance between intrinsic and extrinsic factors.

9. The circles on the arrows in Fig. 1 are not uniform and represent that one factor may be more predominant than another [17]. 
10. The relevant factors are defined during the material's processing and characterization [18].

\section{Final Remarks}

11. Optimized properties in advanced ceramics require know-how on the influence of intrinsic and extrinsic factors.

\section{Open Invitation}

Review, add content, and co-author this paper [19].

Join the Open Engineering Collaboration.

Send your contribution to andre@selfchargebox.com.

\section{Open Science}

The latex file for this paper together with other supplementary files are available [20].

\section{Agreement}

12. All authors agree with [21].

\section{References}

[1] Somiya, S. "Handbook of advanced ceramics: materials, applications, processing, and properties." Academic press., 02 Oct. 2020. https://doi .org/10.1016/C2010-0-66261-4

[2] Serrano, A. G., et al. "Microstructural, structural and electrical properties of bilayered Ba Zr0.05 Ti0.95 O3/Ba0.75 Sr0.25 TiO3 ceram- 
ics." Materials Research Bulletin., 05 Oct. 2020.

https://doi.org/10.1016/j.materresbull.2016.11.016

[3] Haertling, G. H. "Ferroelectric ceramics: history and technology." Journal of the American Ceramic Society., 06 Oct. 2020. https://doi.org/10.1111/j.1151-2916.1999.tb01840.x

[4] Colombo, P., et al. "Multifunctional advanced ceramics from preceramic polymers and nano-sized active fillers." Journal of the European Ceramic Society., 02 Oct. 2020.

https://doi.org/10.1016/j.jeurceramsoc.2012.10.006

[5] Padture, N. P. "Advanced structural ceramics in aerospace propulsion." Nature materials., 02 Oct. 2020.

https://doi.org/10.1038/nmat4687

[6] Sakabe, Y. "Multilayer ceramic capacitors." Current Opinion in Solid State and Materials Science., 05 Oct. 2020.

https://doi .org/10.1016/S1359-0286(97)80049-6

[7] Randall, C. A., et al. "Intrinsic and extrinsic size effects in finegrained morphotropic-phase-boundary lead zirconate titanate ceramics." Journal of the American Ceramic Society., 09 Oct. 2020. https://doi.org/10.1111/j.1151-2916.1998.tb02389.x

[8] Da Silva, L. F., et al. "Insight into the effects of Fe addition on the local structure and electronic properties of SrTiO3." The Journal of Physical Chemistry C., 01 Oct. 2020.

https://doi.org/10.1021/jp408839q

[9] Picht, G., et al. "Structural properties of (Bi0.5Na0.5) 1 - xBaxTiO3 lead-free piezoelectric ceramics." Journal of the European Ceramic Society., 09 Oct. 2020.

https://doi.org/10.1016/j.jeurceramsoc.2010.07.042 
[10] Milošević, O. and Uskoković, D. "Synthesis of BaTiO3 and ZnO varistor precursor powders by reaction spray pyrolysis." Materials Science and Engineering: A, 05 Oct. 2020.

https ://doi .org/10.1016/0921-5093(93)90736-X

[11] Zheng, P., et al. "Grain-size effects on dielectric and piezoelectric properties of poled BaTiO3 ceramics." Acta Materialia., 01 Oct. 2020. https://doi.org/10.1016/j .actamat.2012.06.015

[12] Johnson-Wilke, R. L., et al. "Ferroelectric/Ferroelastic domain wall motion in dense and porous tetragonal lead zirconate titanate films." IEEE transactions on ultrasonics, ferroelectrics, and frequency control., 09 Oct. 2020.

https://doi.org/10.1109/TUFFC.2014.006562

[13] Ohji, T. and Fukushima, M. "Macro-porous ceramics: processing and properties." International Materials Reviews., 01 Oct. 2020. https://doi.org/10.1179/1743280411Y.0000000006

[14] Lukić, M. J., et al. "Processing route to fully dense nanostructured HAp Bioceramics: From powder synthesis to sintering." Journal of the American Ceramic Society., 09 Oct. 2020. https://doi.org/10.1111/j.1551-2916.2012.05376.x

[15] Link, G., et al. "Sintering of advanced ceramics using a 30-GHz, 10-kW, CW industrial gyrotron." IEEE Transactions on Plasma Science., 07 Oct. 2020. https://doi.org/10.1109/27.772284

[16] Rubio-Marcos, F., et al. "Understanding the piezoelectric properties in potassium-sodium niobate-based lead-free piezoceramics: Interrelationship between intrinsic and extrinsic factors." Journal of the European Ceramic Society., 08 Oct. 2020.

https://doi.org/10.1016/j.jeurceramsoc. 2017.04.045

[17] Zhan, Di., et al. "Contributions of intrinsic and extrinsic polarization species to energy storage properties of Ba0.95 Ca0.05 Zr0.2 Ti0.8 O3 
ceramics." Journal of Physics and Chemistry of Solids., 11 Oct. 2020. https://doi.org/10.1016/j.jpcs.2017.10.038

[18] Carter, C. B., et al. "Ceramic Materials: science and engineering." Springer., 02 Oct. 2020.

https://doi.org/10.1007/978-1-4614-3523-5

[19] Bonaventura, A. L. , et al. "Properties of advanced ceramics concerning intrinsic and extrinsic factors." OSF Preprints., 13 Oct. 2020. https://doi.org/10.31219/osf .io/xt7h6

[20] Lobo, Matheus P. "Open Journal of Mathematics and Physics (OJMP)." OSF, 21 Apr. 2020.

https://doi.org/10.17605/osf .io/6hzyp

[21] Lobo, Matheus P. "Simple Guidelines for Authors: Open Journal of Mathematics and Physics." OSF Preprints, 15 Nov. 2019.

https://doi.org/10.31219/osf .io/fk836

\section{The Open Engineering Collaboration}

André Luis Bonaventura (lead author, andre@selfchargebox.com) $)^{1,2}$ https://orcid.org/0000-0001-9255-4737

Rangel Graudiston Aredes (rangel.aredes@gmail.com) ${ }^{1}$

https://orcid.org/0000-0003-0459-1023

Eduardo Antonelli (antonelli@unifesp.br) ${ }^{1}$

https://orcid.org/0000-0001-5029-1115

${ }^{1}$ Advanced Ceramic Laboratory, Science and Technology Institute, Federal University of São Paulo

${ }^{2}$ Self Charge Box, StartUp, São José dos Campos, SP, Brazil. 